\title{
Toward a Connected System-Understanding the Contribution of Light from Different Sources on Occupants' Circadian Rhythms
}

\author{
Wenye $\mathrm{Hu}^{*}$ (D) and Wendy Davis
}

check for

updates

Citation: Hu, W.; Davis, W. Toward a Connected System-Understanding the Contribution of Light from Different Sources on Occupants' Circadian Rhythms. Appl. Sci. 2021, 11, 9939. https://doi.org/10.3390/ app11219939

Academic Editors: Tran Quoc Khanh, Vinh Quang Trinh and

Sebastian Babilon

Received: 29 September 2021

Accepted: 22 October 2021

Published: 25 October 2021

Publisher's Note: MDPI stays neutral with regard to jurisdictional claims in published maps and institutional affiliations.

Copyright: (c) 2021 by the authors. Licensee MDPI, Basel, Switzerland. This article is an open access article distributed under the terms and conditions of the Creative Commons Attribution (CC BY) license (https:// creativecommons.org/licenses/by/ $4.0 /)$.
School of Architecture, Design and Planning, The University of Sydney, Sydney, NSW 2006, Australia; wendy.davis@sydney.edu.au

* Correspondence: wenye.hu@sydney.edu.au

Featured Application: The real-world data collected in this study provide a general understanding of the contribution of light from different sources on office occupants' circadian rhythms. The outcomes demonstrate that conventional electric lighting systems predominantly providing light downward have limited circadian effects, which suggests that human-centric lighting systems that solely rely on adjustments of electric lighting may be ineffective. Connected smart systems controlling the light from electric lighting systems, computer displays, and daylight should be developed to optimize the circadian effects of lighting in architectural spaces.

Abstract: Light that enters humans' eyes and impacts circadian rhythms may come from various sources, including the sun, electric lighting systems, and self-luminous displays. Occupants' activities strongly impact the light entering their eyes, which is difficult to predict and not yet well understood. This study investigated the circadian contributions of light from different sources in real building environments to better understand the variables that influence the circadian health of occupants. Spectral irradiance distributions at a position equivalent to the front of an eye of a seated occupant in various interior office spaces were collected. Daylight and electric light were measured separately, and light emitted from displays was measured when a variety of different computer tasks was performed. Circadian stimulus (CS) and $\alpha$-opic irradiance, defined by CIE DIS026/E:2018, were further calculated, and the circadian effects of light from different sources were compared. The results show that daylight has the greatest circadian effect, while electric light in spaces that were predominantly designed with conventional downward lighting has a very limited impact. The circadian effect of light from screens was considerably high. The outcomes suggest that, to optimise the circadian effects of light, connected lighting systems are needed to control light from different sources.

Keywords: circadian rhythms; daylight; displays; circadian stimulus; spectral irradiance; human-centric lighting

\section{Introduction}

Scientific evidence clearly shows that light impacts human circadian rhythms [1-5]. Within the lighting industry, there is much enthusiasm for manipulating the spectral output of electric lighting systems to improve the health of building occupants [6]. However, using light to improve human's well-being is more complicated in real architectural spaces because light comes from various sources, including daylight, electric light, and selfluminous displays. Additionally, the light entering humans' eyes is influenced by their movements and activities. In the real world, building occupants may roll down window shades, close blinds, turn their backs to windows, dim the electric light, tilt laptop screens, etc. Although studies have been conducted to investigate the circadian effects of daylight and electric lighting, field studies in real architectural spaces to compare the influences 
of light from different sources are limited. The lack of empirical data makes the design of human-centric lighting and the development of innovative products challenging. This research aims to understand the effect of light from different sources on human circadian rhythms in office settings, based on field measurements. The outcomes of this work may guide the development of innovative human-centric lighting systems.

Daylight, which has a changing spectrum over the day, has a significant impact on circadian physiology and cognitive performance [7]. One study concluded that one half hour of daylight exposure could reduce sleepiness in the afternoon [8]. It is currently possible to predict the intensity and spectrum of daylight for a specific location in a building using computer simulations. However, data presented in multiple studies showed that occupants frequently use window coverings to block solar radiation in response to both visual and thermal comfort considerations $[9,10]$. Those calculations and predictions rarely consider these types of interventions or occupants' activity patterns.

Based on Newsham's original work [11], Reinhart developed an algorithm to predict the use of electric lighting based on observations of window blind usage patterns in actual office buildings [12]. The author acknowledged the limitations of this algorithm, which can only be applied to private and two-person offices [12]. The model only assumed that users kept the blinds either fully opened or closed, neglecting the fact that sometimes occupants partially lower window shades. Because Reinhart's research was focused on energy performance, only illuminance on working planes was studied, not the spectra of light [12].

A field study was conducted in four office buildings, in which the spectra and luminous flux of light sources varied [13]. As shown in a photo of the site, offices were illuminated by typical overhead fluorescent troffers. Most participants had little or no access to daylight. The intervention lighting provided by portable desk luminaires and/or newly installed overhead luminaires was added to the existing lighting to ensure that the circadian stimulus (CS) of light incident upon the occupants' eyes was greater than 0.3. When office workers were exposed to such intervention lighting for two days, their subjective vitality and alertness were increased, and their self-reported sleepiness was reduced [13].

A field study was conducted in a university dormitory in Beijing, China [14]. Wireless sensors were used in each bed to record the illuminance at the head position. Subjects' sleep quality, alertness and mood were evaluated using the Pittsburgh Sleep Quality Index, Karolinska Sleepiness Scale and Positive and Negative Semantic Scales. The researchers concluded that daylight exposure before awakening in summer significantly influenced subjects' alertness, mood and deep sleep duration, but it did not impact these indexes in winter [14]. This research demonstrated that daylight affects occupants' circadian systems, but it did not measure the spectrum of light, which changes throughout the day and across seasons, due to equipment limitations.

Some studies have compared the effects of daylight and electric lighting on human circadian systems. Borisuit et al. [15] found that subjects exposed to daylight during the daytime were more alert at the beginning of the evening than those lit by electric light. They further reported that subjects who were exposed to daylight earlier in the day felt sleepy later than those illuminated by electric light [15]. However, this study did not report sufficient circadian related metrics for the lighting conditions.

Bellia et al. measured irradiance, correlated colour temperature of the light, vertical illuminance at eye height, and horizontal illuminance $0.8 \mathrm{~m}$ above the floor in a classroom on two typical winter days, under daylight conditions and electric lighting conditions [16]. Their study provided valuable empirical data comparing the circadian effects of daylight and electric light. The results demonstrated that daylight led to greater calculated melatonin suppression. However, the daylight data were collected by pointing instruments "on the section of the sky visible through the classroom windows" [16]. This may overestimate the effect of daylight in real applications because occupants do not always face windows, and 
reflections off large internal surfaces in buildings (e.g., walls) may alter the spectrum of light.

In Boubekri and colleagues' research [17], each participant wore an Actiwatch-L, which is a wrist-worn device equipped with a photodiode, for two weeks. The intensity and duration of light exposure were recorded when participants performed normal daily activities. The researchers found that low amounts of daylight exposure in offices led to reduced sleep duration, poorer sleep quality and lower activity levels [17]. However, they acknowledged that the light exposure data collected by devices worn on wrists may not fully represent the light reaching the retina. Additionally, the daylight and electric light were not analysed separately due to equipment limitations. Therefore, they suggested that future research collect spectral measurements of daylight and electric light independently using devices located in positions similar to those of people's eyes [17].

Given the widespread uses of computers, tablets and mobile phones [18], these increasingly bright screens, such as those with a peak luminance of $1000 \mathrm{~cd} / \mathrm{m}^{2}$ [19], likely also play an important role in influencing occupants' circadian rhythms. Sivaji et al. investigated office workers' task performance using a computer under three lighting conditions: $2700 \mathrm{~K}, 4000 \mathrm{~K}$ and $6200 \mathrm{~K}$ [20]. One of their conclusions was that $2700 \mathrm{~K}$ light can notably increase users' alertness, as the data showed that participants had the fewest typing errors in a typing test when illuminated by $2700 \mathrm{~K}$. The authors noted that this result was not in accordance with other research in the scientific literature. It is commonly accepted that short wavelength light suppresses the production of the hormone melatonin, which should theoretically increase people's alertness. The authors explained that their findings might be caused by their small sample size ( 10 subjects). However, there might be other explanations, such as the light from the screens dominating the electric lighting, negating any differences in performance caused by the illumination that may be otherwise observed.

Some researchers have investigated the circadian effects of self-luminous tablets, but their studies have led to mixed results and debate. One study found that reading on an iPad for $30 \mathrm{~min}$ before bed resulted in decreased subjective sleepiness and delayed electroencephalography (EEG) dynamics of slow-wave activity compared with reading a paper book [21]. Wood and colleagues [22] examined 13 participants' melatonin levels after using self-luminous tablets for two time conditions: one hour and two hours. Suppression of melatonin levels after one hour of exposure was not significant, but it was significant after two hours of use [22]. Cajochen et al. reported that exposure to an LED-backlit screen for five hours in evenings resulted in reduced salivary melatonin and sleepiness levels, but increased cognitive performance, including improved sustained attention, as well as working and declarative memory [23]. Rångtell's team [24] measured evening concentration of melatonin in the saliva of 14 subjects after exposure to bright light ( 569 lx) over $6.5 \mathrm{~h}$ followed by reading on a tablet or from a book for two hours (21:00-23:00). No differences in sleepiness and salivary melatonin levels were found between the tablet and book conditions. They explained that the exposure to bright light during the day might combat sleep disturbances associated with the use of blue-light-emitting electronic devices in the evening [24].

Chang et al. reported that reading on light-emitting devices suppressed evening levels of melatonin by $55.12 \% \pm 20.12 \%$, while reading on a book was associated with no suppression [25]. These researchers further concluded that it took longer for participants to fall asleep after reading on light-emitting devices and that their evening sleepiness, melatonin secretion and next-morning alertness were all reduced [25]. In Chang and colleagues' study, participants lived in a controlled environment (in the Intensive Physiological Monitoring Unit of the Centre for Clinical Investigation of Brigham and Women's Hospital) for 14 days. Thus, Zeitzer argued that the effect of light-emitting devices has been overestimated because "real-life light exposure desensitizes the non-image-forming system to the intensity of evening light exposure that was examined in this study" [26]. He suggested that the results of this study cannot be generalised to answer the question of whether the use of self-luminous devices at night negatively impacts sleep [26]. 
Though the experimental protocol of Chang et al. was well-designed as a mechanistic study and greatly contributed to the growing literature, Zeitzer's argument did highlight the lack of field studies on light exposure in real applications. The circadian effects of light from daylight, electric light sources and self-luminous displays in real-world settings are unclear because little empirical data is available. The present study aims to understand typical light exposure and compare the range and distribution of the circadian effects of light from these three sources in real commercial and residential office spaces.

\section{Materials and Methods}

In 2002, scientists discovered a new type of photoreceptor-intrinsically photoreceptive retinal ganglion cells (ipRGCs), which play an important role in the nonvisual responses to light [27]. However, the action spectrum of ipRGCs alone is insufficient to assess the magnitude of nonvisual responses to light because the firing rate of ipRGCs is also influenced by the four other types of photoreceptors-rods, S-cones, M-cones and L-cones. Thus, the International Commission on Illumination (CIE) developed a light measurement system in which the responses of all five photoreceptor types are characterised to assess nonvisual responses to light [28]. The CIE recommended that spectral measurements, in the form of spectral irradiance distributions (SIDs), be carefully collected and recorded for research relating to the circadian effects of light [29].

In this study, SIDs were collected in various interior spaces, including open plan and cellular offices in six commercial buildings, as well as home offices in four residential buildings. In these applications, users typically sit at desks and face computer displays. The environment (e.g., positions of window shading devices, furniture layouts) remained as it was during the typical use of these spaces. Spectral irradiance distributions were measured from a position equivalent to the front of an eye of a seated occupant. To do so, a spectral irradiance meter (Konica Minolta CL-500A) was mounted approximately $30 \mathrm{~cm}$ above the desk surface on an adjustable chin rest, which was installed at the edge of each desk.

Daylight was measured with the interior electric lights switched off. The measurements were conducted automatically every ten minutes. Measurements of electric lighting were conducted at night, and the window coverings were closed if there was any light from external lighting sources. Because the spectrum of electric light is relatively stable, the SIDs for illumination from electric light were measured three times for each condition. For the spectrally tuneable lighting system, SIDs were collected under three control settings: warm white light (measured $2762 \mathrm{~K}$ ), neutral white light (measured $3968 \mathrm{~K}$ ), and cool white light (measured $6253 \mathrm{~K}$ ). Laptop and desktop computers from different manufacturers were used in this study to generally understand the effects of currently commercially available displays. The spectrum of light emitted from a display is highly dependent on the tasks undertaken on the computer. A variety of different computer tasks were conducted when the SIDs were recorded in five-minute measurement intervals. Typical computer tasks in offices include website browsing, word processing, reading, writing emails, etc. Some industries, such as architectural design, involve the use of design software with default black backgrounds. In home offices, computer displays also commonly perform some recreational activities, such as streaming videos. Thus, the SIDs were measured separately when typical office tasks were simulated, when black-background software was used, and when videos were displayed. To account for changes in the spectrum over time, the measurements of displays were taken for between one and five hours. In total, 394 SIDs at eye height were collected when only daylight was measured, 80 SIDs were collected under solely electric light, and 134 SIDs were recorded of the light solely from computer screens.

The $\alpha$-opic irradiance was calculated for each measurement condition using Equation (1), as recommended in CIE DIS 026/E:2018 [28],

$$
E_{e, \alpha}=\int E_{e, \lambda}(\lambda) S_{\alpha}(\lambda) d \lambda
$$


where $E_{e, \lambda}(\lambda)$ is the spectral irradiance at a point in space, $S_{\alpha}(\lambda)$ is the $\alpha$-opic action spectrum defined by CIE, and $E_{e, \alpha}$ is the effective photobiological irradiance at the point in space.

Although the CIE system defines quantities and spectral sensitivity functions to precisely describe the radiation that influences humans' circadian rhythms, it does not directly quantify the influence on the circadian system [28]. Rea et al. developed a mathematical model, converting the spectral irradiance at the cornea to a circadian stimulus (CS) metric, as expressed in Equations (2) and (3), which is purported to be proportional to nocturnal melatonin suppression $[2,30]$.

$$
C L_{A}=\left\{\begin{array}{c}
C S=0.7-\frac{0.7}{1+\left(\frac{C L_{A}}{355.7}\right)^{1.1026}} \\
1548\left[\int M_{C \lambda} E_{\lambda} d \lambda+\left(a_{b-y}\left(\int \frac{S_{\lambda}}{m p_{\lambda}} E_{\lambda} d \lambda-k \int \frac{V_{\lambda}}{m p_{\lambda}} E_{\lambda} d \lambda\right)-a_{r o d}\left(1-e^{\frac{-\int V^{\prime} E_{\lambda} d \lambda}{\operatorname{Rodsat}_{a}}}\right)\right)\right], \\
\text { if } \int \frac{S_{\lambda}}{m p_{\lambda}} E_{\lambda} d \lambda-k \int \frac{V_{\lambda}}{m p_{\lambda}} E_{\lambda} d \lambda>0 \\
1548 \int M_{C \lambda} E_{\lambda} d \lambda \\
\text { if } \int \frac{S_{\lambda}}{m p_{\lambda}} E_{\lambda} d \lambda-k \int \frac{V_{\lambda}}{m p_{\lambda}} E_{\lambda} d \lambda \leq 0
\end{array}\right.
$$

where

$C L_{A}$ is circadian light,

$C S$ is circadian stimulus,

$E_{\lambda}$ is the SID of the incident light,

$M_{C \lambda}$ is melanopsin sensitivity (corrected for crystalline lens transmittance),

$S_{\lambda}$ is the S-cone fundamental,

$m p_{\lambda}$ is the transmittance of macular pigment,

$V_{\lambda}$ is the photopic luminous efficiency function,

$V_{\lambda}^{\prime}{ }_{\lambda}$ is the scotopic luminous efficiency function,

RodSat is the half-saturation constant for bleaching rods, equal to $6.5 \mathrm{~W} / \mathrm{m}^{2}$,

$k$ equals 0.2616 ,

$a_{b-y}$ equals 0.7 and

$a_{\text {rod }}$ equals 3.3 [2].

Because all known photopigments affect human circadian systems, Equation (3) includes the contribution of all photopigments. $a_{r o d}\left(1-e^{\frac{-\int V^{\prime} E_{\lambda} d \lambda}{R o d s a t}}\right)$ serves as a threshold for rod bleaching. Above the threshold, cone responses are processed through the opponent blue-yellow color mechanism, expressed as $a_{b-y}\left(\int \frac{S_{\lambda}}{m p_{\lambda}} E_{\lambda} d \lambda-k \int \frac{V_{\lambda}}{m p_{\lambda}} E_{\lambda} d \lambda\right)$. The output of the blue-yellow mechanism is added to the ipRGCs responses only when $\int \frac{S_{\lambda}}{m p_{\lambda}} E_{\lambda} d \lambda-k \int \frac{V_{\lambda}}{m p_{\lambda}} E_{\lambda} d \lambda>0$. More details of the CS metric are reported in Rea and Figueiro's publications [2,31].

As a measure of the effectiveness of the light on the circadian system, CS ranges from 0.1 , which is the minimum exposure level for reliable measurements of nocturnal melatonin suppression, to saturation at 0.7 [30]. Figueiro et al. stated that their CS model was based on the assumption that a "light stimulus that evokes acute melatonin suppression has similar characteristics to the light stimulus needed to promote entrainment." However, this assumption has not yet been validated.

The CIE defined five smooth action spectra based on the melanopic sensitivity function of Lucas et al. [4]. Two earlier independent studies, investigating the spectral sensitivity of melatonin suppression, both showed an obvious discontinuity in the data at about $505 \mathrm{~nm}[32,33]$. Rea and Figueiro pointed out that this is not a coincidence [2]. Their theory, which applies an understanding of opponent colour vision channels (blue-yellow, in this case), is able to explain this discontinuity because the light at this wavelength appears green, which is neither blue nor yellow. They believe that the blue-yellow opponent colour channel plays an important role in human circadian phototransduction. Thus, they 
included this consideration in the CS calculations. At present, both Rea and Figueiro's method and the CIE system have limitations and neither method is universally accepted. In this study, both $\alpha$-opic irradiance and circadian stimulus were calculated.

\section{Results}

The average melanopic irradiance at the equivalent eye position were $0.194 \mathrm{~W} / \mathrm{m}^{2}$, $0.037 \mathrm{~W} / \mathrm{m}^{2}$, and $0.087 \mathrm{~W} / \mathrm{m}^{2}$, for daylight, electric lighting, and light from displays, and the average $C S$ values were $0.175,0.037$, and 0.114 , respectively. For the conditions measured, daylight has the greatest circadian effect, while electric lighting has the least. Light from computer screens has less impact than daylight but considerably higher impact than electric light.

For the spaces measured, the effect of light on circadian rhythms in offices in commercial buildings was much greater than the effect in home offices in residential buildings, as shown in Table 1. The average CS values in the home offices are all below the threshold (0.1), which suggests that the circadian effect of light is limited in current residential buildings.

Table 1. The average $\alpha$-opic irradiance and circadian stimulus (CS) for daylight, electric lighting, and light from displays in home offices in residential buildings and offices in commercial buildings, as measured at the eye position.

\begin{tabular}{|c|c|c|c|c|c|c|c|}
\hline & & $\begin{array}{c}C S \\
\text { (Unitless) }\end{array}$ & $\begin{array}{c}\text { Melanopic } \\
\text { Irradiance } \\
\left(\mathrm{W} / \mathrm{m}^{2}\right)\end{array}$ & $\begin{array}{l}\text { S-Cone-Opic } \\
\text { Irradiance } \\
\left(\mathrm{W} / \mathrm{m}^{2}\right)\end{array}$ & $\begin{array}{l}\text { M-Cone-Opic } \\
\text { Irradiance } \\
\left(\mathrm{W} / \mathrm{m}^{2}\right)\end{array}$ & $\begin{array}{l}\text { L-Cone-Opic } \\
\text { Irradiance } \\
\left(\mathrm{W} / \mathrm{m}^{2}\right)\end{array}$ & $\begin{array}{c}\text { Rhodopic } \\
\text { Irradiance } \\
\left(\mathrm{W} / \mathrm{m}^{2}\right)\end{array}$ \\
\hline \multirow{3}{*}{$\begin{array}{l}\text { Residential } \\
\text { buildings }\end{array}$} & Daylight & 0.053 & 0.041 & 0.023 & 0.053 & 0.063 & 0.047 \\
\hline & Electric light & 0.004 & 0.003 & 0.001 & 0.006 & 0.009 & 0.004 \\
\hline & Computer screen & 0.049 & 0.032 & 0.022 & 0.041 & 0.047 & 0.037 \\
\hline \multirow{3}{*}{$\begin{array}{l}\text { Commercial } \\
\text { buildings }\end{array}$} & Daylight & 0.296 & 0.346 & 0.204 & 0.408 & 0.463 & 0.387 \\
\hline & Electric light & 0.070 & 0.071 & 0.043 & 0.125 & 0.159 & 0.091 \\
\hline & Computer screen & 0.180 & 0.142 & 0.095 & 0.176 & 0.201 & 0.165 \\
\hline
\end{tabular}

Anderson-Darling tests were conducted in MATLAB to determine whether each set of data has a normal distribution. The null hypothesis that the population data are normally distributed was rejected at the 5\% significance level. Statisticians suggest that median and quartile values are extremely useful for measuring and describing skewed data that is not perfectly normally distributed [34]. Therefore, the distribution of the $\alpha$-opic irradiance and circadian stimulus for each condition in commercial offices is shown in a box and whisker plot in Figure 1. The inter-quartile ranges for daylight and light from displays are wide because of their dynamic nature. Daylight changes in intensity and spectrum throughout the day, while the screen output changes with the computer tasks. The interquartile range of melanopic irradiance for daylight is $0.180 \mathrm{~W} / \mathrm{m}^{2}$ to $0.388 \mathrm{~W} / \mathrm{m}^{2}$, which is considerably higher than the interquartile range for electric light (from $0.028 \mathrm{~W} / \mathrm{m}^{2}$ to $0.099 \mathrm{~W} / \mathrm{m}^{2}$ ). Figueiro suggested that exposure to light with a CS greater than 0.3 at the eye position for at least one hour has a significant impact on sleep quality and mood [30]. During the daytime, the median CS caused by daylight was 0.266 . This suggests that daylight's circadian effect in typical windowed offices in commercial buildings is probably sufficient or nearly sufficient if the exposure time is longer than one hour. 


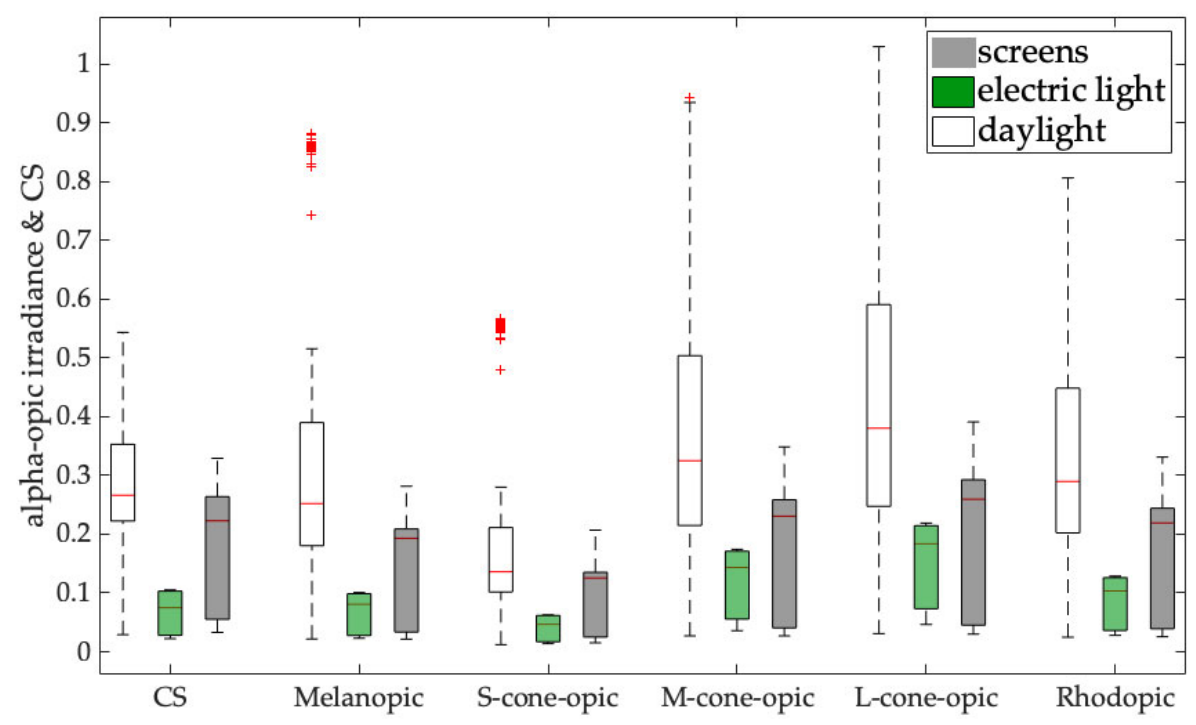

Figure 1. The $\alpha$-opic irradiance and circadian stimulus (CS) for each of the three main sources of light in offices in commercial buildings. The red horizontal lines that divide the boxes into two parts mark the median (middle quartile). The boxes represent the inter-quartile range (the middle 50\%) and the upper and lower whiskers show the highest and lowest non-outliers. The red crosses outside the boxes show the outliers.

It can be seen from Figure 1 that the median $C S$ and melanopic irradiance for screens are higher than the medians for electric light, though the former's interquartile range is also larger. Although the circadian effects of light from displays vary drastically based on the computer tasks undertaken, their impact generally outweighs the impact of electric light when users sit at a desk and use computers. In certain circumstances, when typical tasks were performed in offices, light from computer screens even had a larger effect than daylight. For instance, on a sunny day, when an occupant sat with their back to the window, the melanopic irradiance at the eye position from daylight alone was $0.178 \mathrm{~W} / \mathrm{m}^{2}(C S=0.224)$, while the melanopic irradiance from the screen light was as high as $0.204 \mathrm{~W} / \mathrm{m}^{2}(C S=0.257)$.

For the same display, the average melanopic irradiance at the eye position when users performed typical office tasks was $0.193 \mathrm{~W} / \mathrm{m}^{2}$, which was, on average, 2.7 times greater than when black-background software was used and 3.7 times greater than when a video was viewed. Figure 2 shows the distribution of $C S$ and melanopic irradiance values at a typical eye position caused by the light from different computer displays, when different tasks were performed on the computers. It is clear that, even across a wide range of products, the display light generally has a strong impact when typical office tasks, such as word processing, reading and writing emails, are undertaken.

This result raises concerns about the possible negative circadian effects on office workers caused by light from screens. Figueiro and colleagues suggested that self-luminous displays may be the primary cause of excessive light exposure during the night [30]. This study provides empirical data to support this supposition. Exposure to bright light at inappropriate times can lead to circadian disruption, which is associated with poor sleep quality, negative mood, and other health risks, such as diabetes, obesity, cardiovascular disease, and cancer [30]. Additionally, the phase of the circadian pacemaker can be delayed by exposure to light within a few hours before the midpoint of the melatonin secretion episode [35]. Office workers who regularly work late may experience these issues because of the light from their computer screens. This study only suggests the possibility of a negative influence on office workers' circadian rhythms based on the measured data and calculation results. Future studies are needed to investigate the circadian impact more directly by analysing salivary/blood melatonin levels and tracking office workers' sleep quality. 


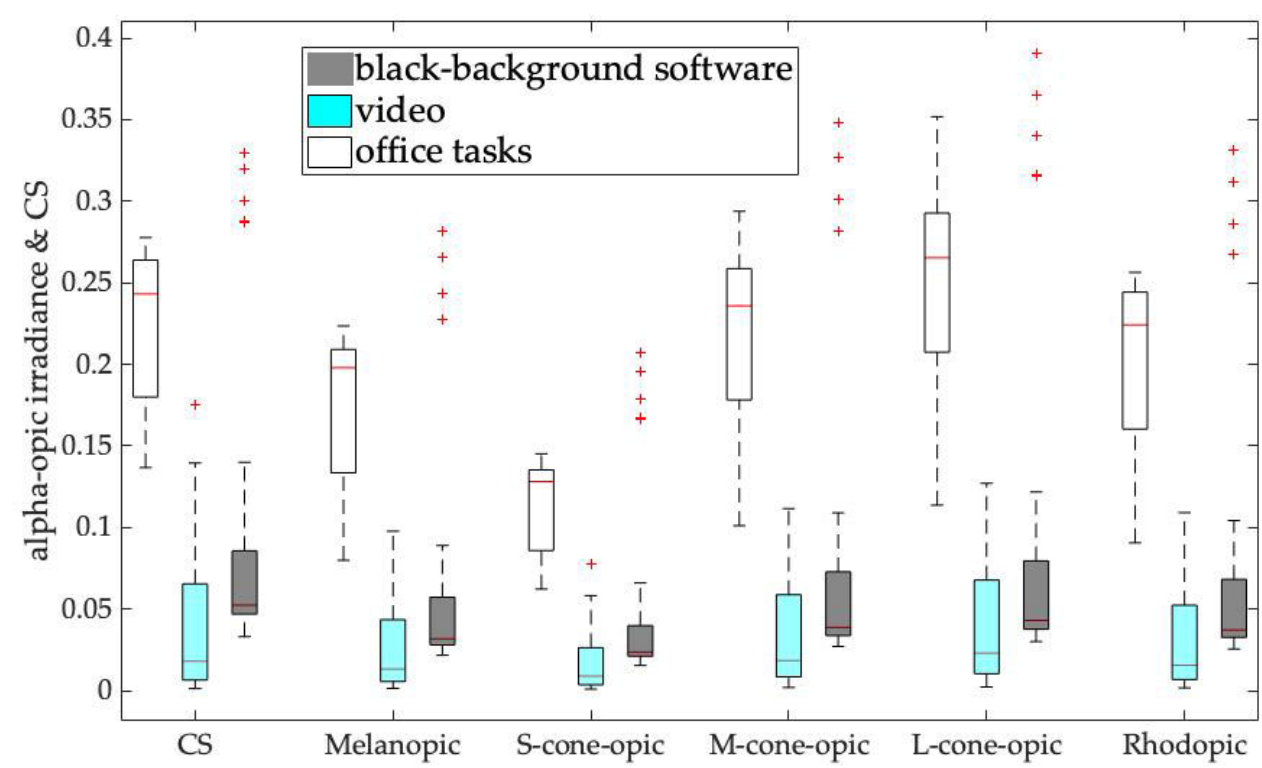

Figure 2. The circadian stimulus (CS) and $\alpha$-opic irradiance caused by the light from different displays when different computer tasks were performed by users. The red horizontal lines that divide the boxes into two parts mark the median (middle quartile). The boxes represent the interquartile range (the middle 50\%) and the upper and lower whiskers show the highest and lowest non-outliers. The red crosses outside the boxes show the outliers.

To further understand the circadian effects of electric lighting, light from a commercially available tuneable white lighting system, which mixes warm-white and cool-white LEDs, was further analysed. The spectral power distributions of three test lighting conditions $(2762$ K, 3968 K, 6253 K) are shown in Figure 3. In a windowless meeting room with constant illuminance, the melanopic irradiance at a modified eye position (simulating reading documents on a desk surface) was $0.133 \mathrm{~W} / \mathrm{m}^{2}, 0.198 \mathrm{~W} / \mathrm{m}^{2}$ and $0.277 \mathrm{~W} / \mathrm{m}^{2}$, when the room was illuminated by $2762 \mathrm{~K}, 3968 \mathrm{~K}, 6253 \mathrm{~K}$ light and the illuminance kept approximately consistent (232 lx, $228 \mathrm{~lx}, 238 \mathrm{~lx}$, respectively). However, the CS values calculated were $0.242,0.194$ and 0.310 , respectively, which indicates a greater circadian impact from the $2762 \mathrm{~K}$ light than the $3968 \mathrm{~K}$ light. This inconsistency in the results between the CIE method and Rea and Figueiro's model is caused by the differences between and limitations of both methods discussed above. Further research needs to be conducted to develop a validated and universally accepted method for quantifying the circadian effects of light.

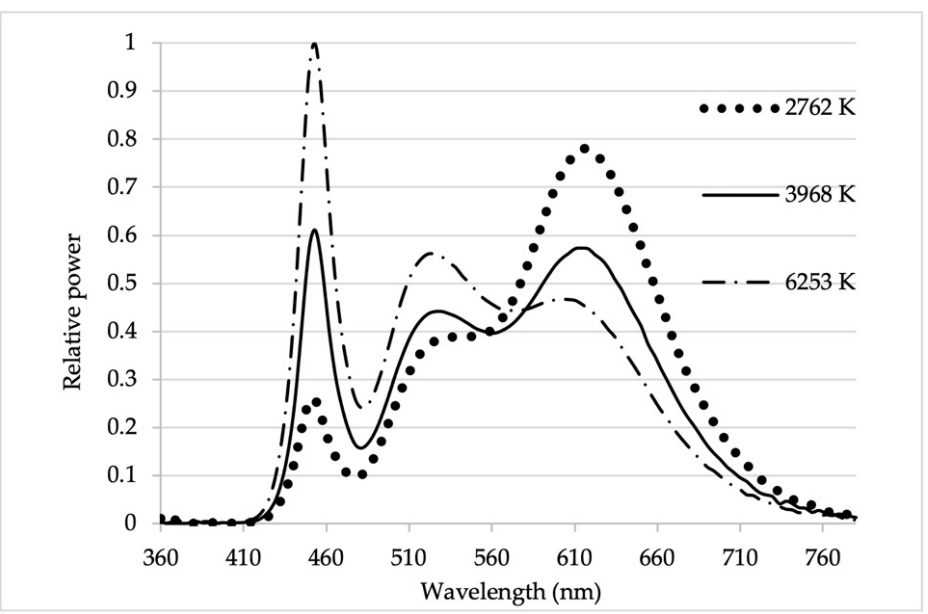

Figure 3. Measured spectral power distributions for $2762 \mathrm{~K}, 3968 \mathrm{~K}$, and $6253 \mathrm{~K}$ light from a commercially available tuneable white lighting system. 


\section{Discussion}

The data collected in this study reveals that the effects of light on occupants' circadian rhythms are limited currently in residential buildings for home offices. It is relatively uncommon for professional designers to be involved in the planning of daylight and electric lighting in residential buildings, which may account for some of the difference. Because more people are working from home and spending increased time in home offices, increased attention on the quality and quantity of lighting in residential buildings is warranted. The result also confirms that daylight strongly influences occupants' circadian rhythms, which has been demonstrated in previous studies [7,14-17].

These results indicate that human-centric lighting systems that only consider the effects of electric light sources are unlikely to appropriately estimate the extent to which occupants' circadian systems are stimulated. The effects of electric light on human circadian rhythms were shown to be weaker than the light from displays and daylight in these field measurements. To most optimally support the circadian health of building occupants, advanced lighting systems should account for all sources of light incident upon people.

The measurements reported here address Zeitzer's concern about the lack of realworld data [26]. The results support Chang and colleagues' conclusion that light-emitting devices do affect users' circadian rhythms [25]. However, rather than being overestimated, as suggested by Zeitzer [26], the effect of light from light-emitting devices is surprisingly large. It can even exceed the effect of overhead electric lighting.

Future internet of things (IoT) systems are expected to connect window shading systems, air conditioning, electric light, and computers together. Such systems could control the window shades, adjusting the amount of daylight in the room to optimise the thermal environment, as well adjust the spectra of light emitted by the computer screens and electric lights, according to changes in daylight. Although it is common today for computers to adjust the luminance of screens automatically in response to ambient brightness, this capability was not primarily developed with the aim of minimising negative impacts on users' circadian rhythms. People who regularly work late can experience delayed sleep phases and poorer sleep quality. With connected IoT systems, when users perform computer tasks in which the circadian effect of the light from the display is high, the electric lighting could be reduced to minimize potential negative circadian impacts. Results from emerging research on spectral optimisation could be potentially adapted to optimise the circadian effect of light and minimise the energy consumed by lighting [36].

This study also reveals that conventional architectural lighting design practices and many current lighting standards do not yield the spatial distribution of light needed in interior spaces to influence circadian rhythms. The electric lighting systems that were measured here were conventional in design and predominantly provided light downward. Though the lighting industry is enthusiastic about human-centric lighting, the data show that, for most typical environments, electric lights' effects on circadian rhythms are limited. Simply replacing the traditional luminaires with spectrally-tuneable variants in retrofit projects may not effectively optimise the effect of lighting on circadian rhythms. The spatial distribution of light needs to be considered, possibly with amendments to lighting standards and regulations. Currently, some standards, such as the WELL Building Standard ${ }^{\mathrm{TM}}$ [37], take the vertical illuminance, converted to equivalent melanopic lux (EML), into account, but most indoor lighting standards only make recommendations regarding horizontal illuminance [38-40]. When electric lighting systems are intended to influence circadian systems, traditional lighting design approaches are unlikely to be effective, even when spectrally tuneable luminaires are used. In such applications, greater consideration of vertical illuminance, particularly at eye level, instead of horizontal illuminance, can considerably increase the circadian effect. However, lighting designers are likely to find it challenging to provide more vertical light at occupants' eye level, while still minimizing glare. Advanced lighting control technologies could be leveraged to develop luminaires capable of dynamically adjusting both light spectra and spatial distribution to provide a 
future solution. However, more studies are needed to guide researchers, manufacturers, and lighting designers.

This study further demonstrates that light from computer screens could be possibly used to offset the energy consumed by lighting for well-being purposes. For example, the WELL Building Standard TM recommends that luminaire(s) in "all bedrooms, bathrooms and rooms with windows" in residential buildings be able to independently achieve at least 200 vertical EML [37]. It is not clear how this recommendation is supported by scientific research, but it is obvious that its implementation would vastly increase the electric energy consumed by lighting systems. If the contribution of light from displays is taken into consideration, an unnecessary increase in energy consumption could be minimized.

Daylight in a space varies with the geographic location of the building, orientation of the rooms, sizes of the windows, time of the day, weather, etc. Bellia noted that the majority of the visual field is occupied by internal surfaces, so the light reaching the eyes highly depends on the reflectance of the internal surfaces [16]. Those factors are not within the scope of this study but may provide the basis for future research.

\section{Conclusions}

Daylight is understood to significantly affect human circadian rhythms. However, the impact of light from the screens of digital devices is also meaningful. In some circumstances, light from computer screens has more influence on office workers' circadian rhythms than either daylight or electric lighting. There are two primary aspects to the optimisation of light for the circadian system: ensuring sufficiently high circadian effective light during daytime and sufficiently low stimulation at night. Light from computer screens meaningfully contributes to circadian entrainment during the daytime. On the other hand, it can also disrupt occupants' circadian systems and negatively impact their sleep quality and sleep patterns. The information collected in this field study shows that none of these light components-daylight, electric light and display light—should be overlooked when designing a human-centric lighting system. A connected IoT system could be developed to integrate various lighting components to improve occupants' well-being and minimise the energy consumption.

Author Contributions: Conceptualization, W.H. and W.D.; Data curation, W.H.; Formal analysis, W.H.; Investigation, W.H. and W.D.; Methodology, W.H. and W.D.; Project administration, W.H.; Resources, W.D.; Software, W.H.; Supervision, W.D.; Validation, W.H. and W.D.; Writing—original draft, W.H.; Writing - review \& editing, W.D. All authors have read and agreed to the published version of the manuscript.

Funding: This research received no external funding.

Institutional Review Board Statement: Not applicable.

Informed Consent Statement: Not applicable.

Data Availability Statement: Raw data supporting the findings of this study will be available on request from the corresponding author.

Conflicts of Interest: The authors declare no conflict of interest.

\section{References}

1. Rea, M.S.; Figueiro, M.G.; Bullough, J.D. Circadian photobiology: An emerging framework for lighting practice and research. Light. Res. Technol. 2002, 34, 177-187. [CrossRef]

2. Rea, M.; Figueiro, M. Light as a circadian stimulus for architectural lighting. Light. Res. Technol. 2018, 50, 497-510. [CrossRef]

3. Van Bommel, W.; Van Den Beld, G. Lighting for work: A review of visual and biological effects. Light. Res. Technol. 2004, 36, 255-266. [CrossRef]

4. Lucas, R.J.; Peirson, S.N.; Berson, D.M.; Brown, T.M.; Cooper, H.M.; Czeisler, C.A.; Figueiro, M.G.; Gamlin, P.D.; Lockley, S.W.; O'Hagan, J.B.; et al. Measuring and using light in the melanopsin age. Trends Neurosci. 2014, 37, 1-9. [CrossRef] [PubMed]

5. Chellappa, S.L.; Steiner, R.; Blattner, P.; Oelhafen, P.; Götz, T.; Cajochen, C. Non-Visual Effects of Light on Melatonin, Alertness and Cognitive Performance: Can Blue-Enriched Light Keep Us Alert? PLoS ONE 2011, 6, e16429. [CrossRef] 
6. Oh, J.H.; Yang, S.J.; Do, Y.R. Healthy, natural, efficient and tunable lighting: Four-package white LEDs for optimizing the circadian effect, color quality and vision performance. Light Sci. Appl. 2014, 3, e141. [CrossRef]

7. Aries, M.; Aarts, M.; van Hoof, J. Daylight and health: A review of the evidence and consequences for the built environment. Light. Res. Technol. 2015, 47, 6-27. [CrossRef]

8. Kaida, K.; Takahashi, M.; Haratani, T.; Otsuka, Y.; Fukasawa, K.; Nakata, A. Indoor exposure to natural bright light prevents afternoon sleepiness. Sleep 2006, 29, 462-469. [CrossRef] [PubMed]

9. Rea, M.S. Window blind occlusion: A pilot study. Build. Environ. 1984, 19, 133-137. [CrossRef]

10. Rubin, A.I.; Collins, B.L.; Tibbott, R.L. Window Blinds as a Potential Energy Saver: A Case Study; U.S. Department of Commerce, National Bureau of Standards: Gaithersburg, MD, USA, 1978.

11. Newsham, G. Manual control of window blinds and electric lighting: Implications for comfort and energy consumption. Indoor Environment 1994, 3, 135-144. [CrossRef]

12. Reinhart, C.F. Lightswitch-2002: A model for manual and automated control of electric lighting and blinds. Sol. Energy 2004, 77, 15-28. [CrossRef]

13. Figueiro, M.G.; Kalsher, M.; Steverson, B.C. Circadian-effective light and its impact on alertness in office workers. Light. Res. Technol. 2018, 51, 171-183. [CrossRef]

14. Dong, Y.; Zhang, X. Study on the effect of awakening daylight in dormitories on morning alertness, mood, fatigue and sleep quality of college students. Build. Environ. 2021, 203, 108060. [CrossRef]

15. Borisuit, A.; Linhart, F.; Scartezzini, J.-L.; Münch, M. Effects of realistic office daylighting and electric lighting conditions on visual comfort, alertness and mood. Light. Res. Technol. 2015, 47, 192-209. [CrossRef]

16. Bellia, L.; Pedace, A.; Barbato, G. Lighting in educational environments: An example of a complete analysis of the effects of daylight and electric light on occupants. Build. Environ. 2013, 68, 50-65. [CrossRef]

17. Boubekri, M.; Cheung, I.N.; Reid, K.J.; Wang, C.-H.; Zee, P.C. Impact of windows and daylight exposure on overall health and sleep quality of office workers: A case-control pilot study. J. Clin. Sleep Med. 2014, 10, 603-611. [CrossRef]

18. Rideout, V.; Foehr, U.; Roberts, D. Generation $m^{2}$ : Media in the Lives of 8- to 18-Year-Olds; Henry, J., Ed.; Kaiser Family Foundation: Oakland, CA, USA, 2010.

19. Nilsson, M. Ultra high definition video formats and standardisation. In BT Media and Broadcast Research Paper; 1Library: Scottsdale, AZ, USA, 2015.

20. Sivaji, A.; Shopian, S.; Nor, Z.M.; Chuan, N.-K.; Bahri, S. Lighting does matter: Preliminary assessment on office workers. Procedia-Soc. Behav. Sci. 2013, 97, 638-647. [CrossRef]

21. Grønli, J.; Byrkjedal, I.K.; Bjorvatn, B.; Nødtvedt, Ø.; Hamre, B.; Pallesen, S. Reading from an iPad or from a book in bed: The impact on human sleeA randomized controlled crossover trial. Sleep Med. 2016, 21, 86-92. [CrossRef]

22. Wood, B.; Rea, M.S.; Plitnick, B.; Figueiro, M.G. Light level and duration of exposure determine the impact of self-luminous tablets on melatonin suppression. Appl. Ergon. 2013, 44, 237-240. [CrossRef] [PubMed]

23. Cajochen, C.; Frey, S.; Anders, D.; Späti, J.; Bues, M.; Pross, A.; Mager, R.; Wirz-Justice, A.; Stefani, O. Evening exposure to a light-emitting diodes (LED)-backlit computer screen affects circadian physiology and cognitive performance. J. Appl. Physiol. 2011, 110, 1432-1438. [CrossRef]

24. Rångtell, F.H.; Ekstrand, E.; Rapp, L.; Lagermalm, A.; Liethof, L.; Búcaro, M.O.; Lingfors, D.; Broman, J.-K.; Schiöth, H.B.; Benedict, $\mathrm{C}$. Two hours of evening reading on a self-luminous tablet vs. reading a physical book does not alter sleep after daytime bright light exposure. Sleep Med. 2016, 23, 111-118. [CrossRef]

25. Chang, A.-M.; Aeschbach, D.; Duffy, J.F.; Czeisler, C.A. Evening use of light-emitting eReaders negatively affects sleep, circadian timing, and next-morning alertness. Proc. Natl. Acad. Sci. USA 2015, 112, 1232-1237. [CrossRef]

26. Zeitzer, J.M. Real life trumps laboratory in matters of public health. Proc. Natl. Acad. Sci. USA 2015, 112, E1513. [CrossRef] [PubMed]

27. Berson, D.M.; Dunn, F.A.; Takao, M. Phototransduction by retinal ganglion cells that set the circadian clock. Science 2002, 295, 1070-1073. [CrossRef] [PubMed]

28. CIE. CIE S 026/E:2018: System for Metrology of Optical Radiation for Iprgc-Influenced Responses to Light; CIE (Commission Internationale de L'Eclairage): Peter Blattner, Switzerland, 2018; p. 36.

29. Price, L. CIE TN003:2015, Report on the First International Workshop on Circadian and Neurophysiological Photometry; CIE (Commission Internationale de L'Eclairage): Peter Blattner, Switzerland, 2015.

30. Figueiro, M.; Steverson, B.; Heerwagen, J.; Kampschroer, K.; Hunter, C.M.; Gonzales, K.; Plitnick, B.; Rea, M.S. The impact of daytime light exposures on sleep and mood in office workers. Sleep Health 2017, 3, 204-215. [CrossRef] [PubMed]

31. Rea, M.S.; Figureio, M.G.; Bierman, A.; Hamner, R. Modelling the spectral sensitivity of the human circadian system. Light. Res. Technol. 2012, 44, 386-396. [CrossRef]

32. Brainard, G.C.; Hanifin, J.P.; Greeson, J.M.; Byrne, B.; Glickman, G.; Gerner, E.; Rollag, M.D. Action spectrum for melatonin regulation in humans: Evidence for a novel circadian photoreceptor. J. Neurosci. 2001, 21, 6405-6412. [CrossRef] [PubMed]

33. Thapan, K.; Arendt, J.; Skene, D.J. An action spectrum for melatonin suppression: Evidence for a novel non-rod, non-cone photoreceptor system in humans. J. Physiol. 2001, 535, 261-267. [CrossRef]

34. Howell, D.C. Statistical Methods for Psychology; Cengage Learning: Boston, MA, USA, 2012. 
35. Figueiro, M.; Overington, D. Self-luminous devices and melatonin suppression in adolescents. Light. Res. Technol. 2016, 48, 966-975. [CrossRef]

36. Dai, Q.; Cai, W.; Hao., L.; Shi, W.; Wang, Z. Spectral optimisation and a novel lighting-design space based on circadian stimulus. Light. Res. Technol. 2018, 50, 1198-1211. [CrossRef]

37. IWBI. The WELL Building Standard ${ }^{\mathrm{TM}}$; The International WELL Building Institute: Hong Kong, China, 2019.

38. Standards Australia. Interior and Workplace Lighting-Specific Applications-Office and Screen-Based Tasks; AS/NZS 1680,2.2:2008; Standards Australia: Sydney, Australia, 2008.

39. Standards Australia. Interior and Workplace Lighting-Specific Applications-Educational and Training Facilities; AS/NZS 1680,2.3:2008; Standards Australia: Sydney, Australia, 2008.

40. National Standards Authority of Ireland. Light and Lighting-Lighting of Workplaces-Part 1: Indoor Workplaces; I.S. EN 12464-1:2011; National Standards Authority of Ireland: Dublin, Ireland, 2011. 